(1)

CrossMark

\title{
A pathway to keep all lifelong learners up to date: the ERS continuing professional development programme
}

\author{
Amy Farr ${ }^{1}$, Stefano Aliberti ${ }^{2,3}$, Stelios Loukides ${ }^{4}$, Gilbert Massard ${ }^{5}$, \\ Robert Primhak ${ }^{6}$, Gernot G.U. Rohde $\mathbb{0}^{7}$, Nathalie Tabin ${ }^{1}$, Carine Pannetier ${ }^{1}$ and \\ Daiana Stolz ${ }^{8}$
}

Affiliations: ${ }^{1}$ European Respiratory Society, Lausanne, Switzerland. ${ }^{2}$ University of Milan, Dept of Pathophysiology and Transplantation, Milan, Italy. ${ }^{3}$ Fondazione IRCCS Ca' Granda Ospedale Maggiore Policlinico, Internal Medicine Dept, Respiratory Unit and Cystic Fibrosis Adult Center, Milan, Italy. "University of Athens, 2nd Respiratory Dept, Athens, Greece. ${ }^{5}$ Dept of Medical Education, Université de Luxembourg, Maison du Savoir, Luxembourg, Luxembourg. ${ }^{6}$ Sheffield, UK. ${ }^{7}$ Dept of Respiratory Medicine, University Hospital, Goethe University, Frankfurt, Germany. ${ }^{8}$ University Hospital Basel, Pulmonary Care Division, Basel, Switzerland.

Correspondence: D. Stolz, University Hospital Basel, Pulmonary Care Division, Petersgraben 4, 4031 Basel, Basel 4031, Switzerland. E-mail: daiana.StolzQusb.ch

@ERSpublications

ERS is committed to offering a lifelong learning pathway for respiratory professionals http://bit.ly/ $36 \mathrm{HghAs}$

Cite this article as: Farr A, Aliberti S, Loukides S, et al. A pathway to keep all lifelong learners up to date: the ERS continuing professional development programme. Eur Respir J 2020; 55: 1902425 [https://doi.org/ 10.1183/13993003.02425-2019].

\begin{abstract}
Albert Einstein's philosophy on lifelong learning was that intellectual growth should commence at birth and cease only at death. Yet in reality, across the board, the foundations of our education systems encourage individual learners early in life to choose a particular path or specialty in a structured way, and then provide little guidance for ongoing development at a more mature stage of their careers. Accordingly, considerable efforts have been invested in identifying relevant content (syllabus) and defining in detail how knowledge and skills are expected to be transferred (curriculum), including: learning objectives, lessons, assignments and learning materials, as well as assessments and other methods, to evaluate learning for the training period up to specialisation in a certain discipline.

Whilst lifelong learning for health professionals could be deemed a given to some, for a large number of respiratory specialists worldwide, there is no guidance on how to keep their knowledge, skills and attitudes up to date after their specialist training. This point is increasingly relevant considering that health professionals are not only finding themselves in the situation of a constant balancing act between integrating a rapidly growing amount of changing information and making decisions; furthermore, with an ageing population, professionals can be active in clinical practice for up to 40 years after concluding specialist training. There is evidence that physicians reach the apex of their knowledge shortly after passing their speciality board exams, which is then followed by a decline in their overall knowledge base [1]. In addition, it was found that the frequency of adverse licensing actions intensifies proportionally to the time spent in practice $[1,2]$. Thus, continuous professional development is a major need in the effort to alleviate suffering from disease and to provide the most efficient and scientifically sound healthcare to the world's population.
\end{abstract}


The European Respiratory Society (ERS) is committed to supporting respiratory professionals in their journey of lifelong learning. This has been demonstrated by over 27 years of dedication to educational content and methods. After having developed over 12 syllabi at in-training levels for both adult and paediatric respiratory medicine, and numerous other subspecialty groups, the ERS recognised the need to provide practical advice on the topics needed to be covered by a general respiratory physician, to assure that their knowledge, skills and attitudes are up to date with current scientific developments. Consequently, the ERS aims to adjust its portfolio of activities to the changing needs of its membership.

Whilst some countries, such as the UK and the Netherlands, have well-defined recertification, licensing or credit systems, and others, such as the USA, count on an obligatory recertification, at least for certain specialities, continuing professional development elsewhere is largely less structured, or even voluntary [3]. Once specialised, health professionals can follow many tracks throughout their career, so although starting from a rather homogeneous knowledge base, respiratory professionals soon end up being a part of a very heterogeneous working environment. Consequently, health professionals require continual professional development (CPD) activities that are modular, constantly updated and relevant to clinical practice, and importantly, in a format that is using the latest technology and medical education principles to ease use and accessibility for busy professionals.

In this regard, key ERS assembly officers worked together to develop the "ERS CPD framework". This framework is expected to drive standards for respiratory medicine globally. The framework focuses not only on the important scientific topics of respiratory medicine, but also on the more intangible and non-technical abilities required to work as a physician, commonly referred to as "soft skills". As is best practice with all educational interventions, it is important to develop faculty and trainers to support the framework development: the ERS Officer Excellence Programme was born [4]. The Excellence Programme aims to empower and educate selected ERS experts on presentation development, facilitation skills, medical education principles, educating with technology and leadership.

The CPD programme is built around the eight respiratory disease areas previously defined by ERS Educational and Scientific Councils (figure 1). This topic division allowed eight focus groups to identify key topics and focus areas [5].

The implementation plans for the eight disease areas will be published by the ERS in Breathe, from December 2019, and further information on the detailed syllabi are now available on the ERS website [6].
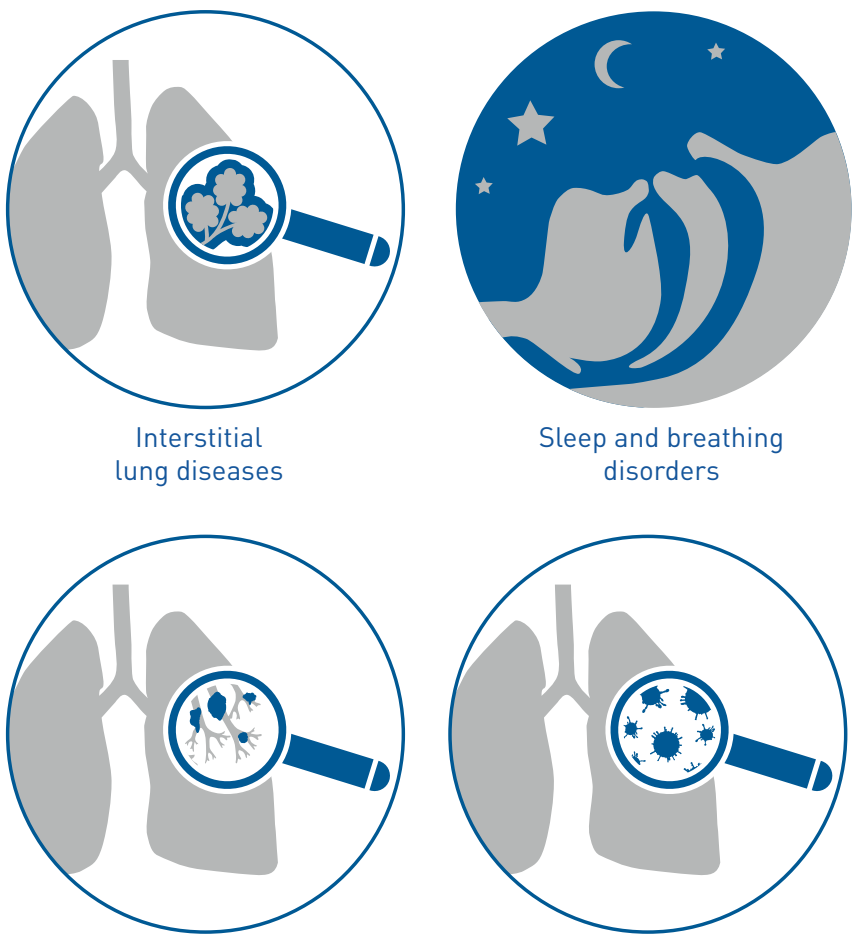

Thoracic oncology
Sleep and breathing disorders

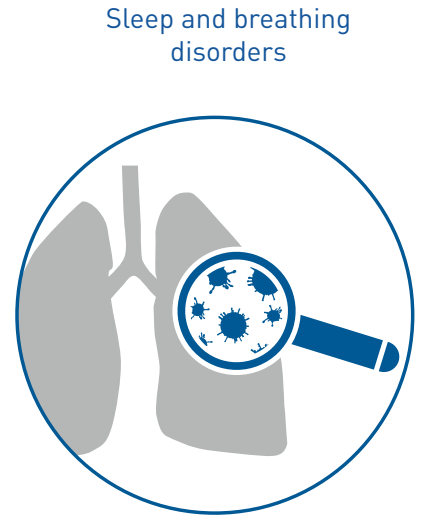

Respiratory infections
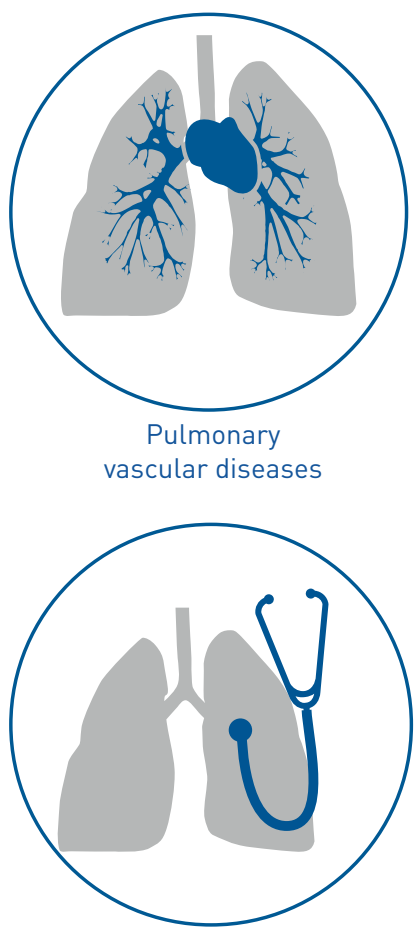

Respiratory critical care
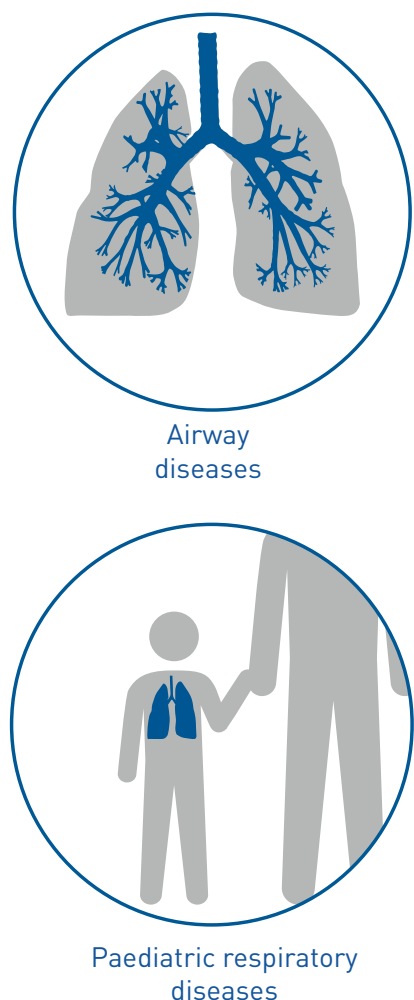


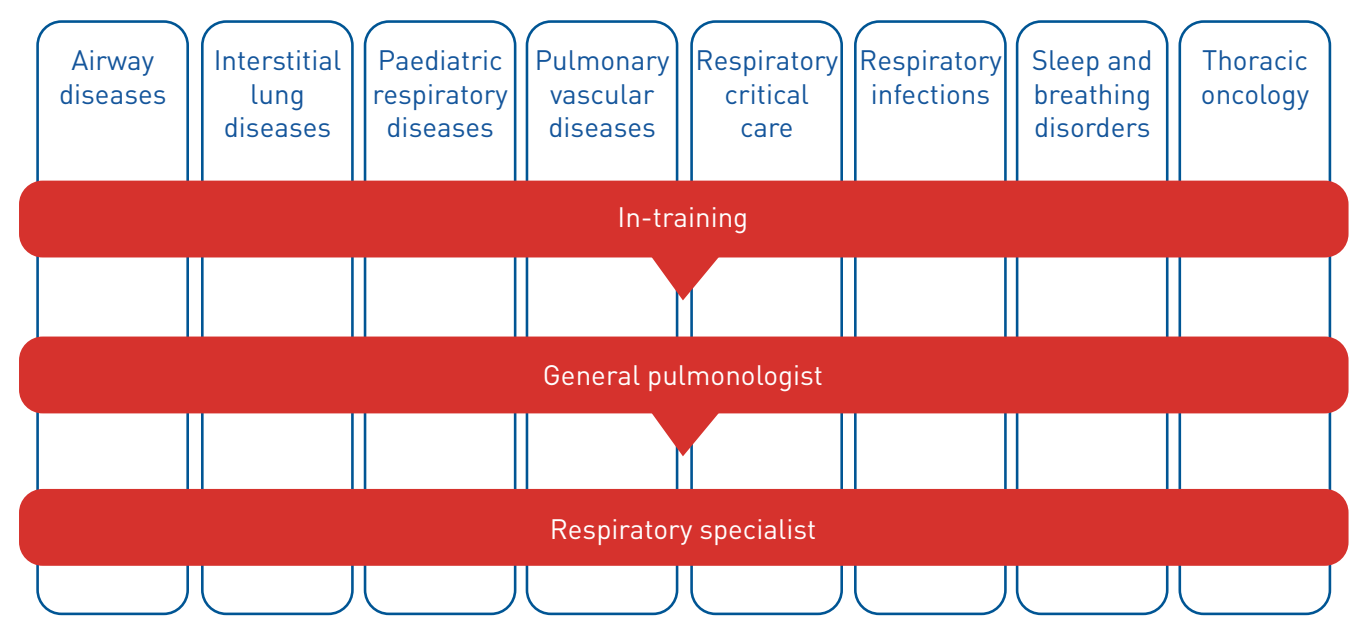

FIGURE 2 The three tiers (in-training, general pulmonologist and specialist) and the eight disease areas, division of knowledge and soft skills.

With the identification of "what" needs to be covered, the ERS assemblies set about developing an implementation plan to develop topics that would be a priority to cover over the next 3-5 years, that would be of major interest for a respiratory physician (figure 2).

Throughout this process, the first-time assembly experts responsible for developing the content across all the disease areas were provided easy access to an overview of all activities which allowed for greater collaboration and information sharing. Today, the implementation is well underway, with key officers now constantly reviewing the portfolio of activities, with regular reporting ingrained within the society's regular Education Council meetings.

At the level of the learner, the respiratory community can now access the entire learning programme and the suggested activities on the ERS website [6]; by selecting a disease area and then topic, learners will be shown content that corresponds. Currently this content has been refined to ERS live events and activities, however, moving forward with the support of an artificial intelligence tool, the ERS is aiming to extend this classification throughout the hundreds of thousands of ERS publications, webcasts, videos, guidelines and other educational content. These syllabi are open access and might be suitable to help national societies and training providers in developing training activities worldwide.

The ERS had, up until 2019, not focused on formalising the structure of ongoing training for respiratory physicians, where the offering is diverse, and the ongoing educational requirements are often not well known. With the development of the ERS CPD programme, the ERS is moving towards supporting the respiratory community along their personalised learning pathway.

Continuing professional development encompasses all the teaching and learning activities that a respiratory professional may follow to ensure that they are up-to-date and in touch with today's clinical practice. CPD is essential for all professionals to ensure better patient care and outcomes.

"Education is the kindling of a flame, not the filling of a vessel." - Socrates

Acknowledgements: The authors would like to the following experts that have contributed to the development of this project: Airway diseases: Fauzi Anshar, Dragos Bumbacea, Antonio Spanevello, Alexander Mathioudakis and Omar Usmani. Interstitial lung diseases: Tiago Alfaro, Katerina Antoniou, Venerino Poletti and Michael Kreuter. Paediatric respiratory diseases: Jonathan Grigg, Alexander Moller, Rakesh Mudgal, Raffaella Nenna and Marielle Pijnenburg. Pulmonary vascular diseases: Marion Delcroix, Marc Humbert, Sheila Ramjug and Anton Vonk Noordegraaf. Respiratory critical care: Lieuwe Bos, Leo M.A. Heunks, Ezgi Ozyilmaz and Raffaele Scala. Respiratory infections: Graham Bothamley, Cristina Calarasu, Pieter Goeminne and Eva Polverino. Sleep and breathing disorders: Andrea Aliverti, Marisa Bonsignore, Pierantonio Laveneziana, Winfried Randerath, Manuel Sánchez-de-la-Torre and Anita Simonds. Thoracic oncology: Torsten Gerriet Blum, Nina Bostantzoglou, Bogdan Dragos Grigoriu, Fernando Gamarra, Georgia Hardavella and Nick Maskell.

Conflict of interest: A. Farr is an employee of the European Respiratory Society. S. Aliberti reports grants and personal fees from Bayer Healthcare, Aradigm Corporation, Grifols, Chiesi and INSMED, personal fees from AstraZeneca, Basilea, Zambon, Novartis, Raptor, Actavis UK Ltd and Horizon, outside the submitted work. S. Loukides has nothing to disclose. G. Massard has nothing to disclose. R. Primhak has nothing to disclose. G.G.U. Rohde reports personal fees from Pfizer, Boehringer Ingelheim, Solvay, GSK, Essex Pharma, MSD, Grifols, Chiesi, Vertex, Roche and Novartis for 
lectures, including service on speakers bureaus and/or consultancy during advisory board meetings, and personal fees from GSK for travel accommodations/meeting expenses, outside the submitted work. N. Tabin is an employee of the European Respiratory Society. C. Pannetier is an employee of the European Respiratory Society. D. Stolz has nothing to disclose.

\section{References}

1 Choudhry NK, Fletcher RH, Soumerai SB. Systematic review: the relationship between clinical experience and quality of health care. Ann Intern Med 2005; 142: 260-273.

2 Van Leeuwen Y, Mol S, Pollemans M, et al. Change in knowledge of general practitioners during their professional careers. Fam Pract 1995; 12: 313-317.

3 Sehlbach C, Govaerts MJ, Mitchell S, et al. Doctors on the move: a European case study on the key characteristics of national recertification systems. BMJ Open 2018; 8: e019963.

4 European Respiratory Society. ERS Officer Excellence Programme. www.ersnet.org/professional-development/oep Date last accessed: 14 August, 2019.

5 European Respiratory Society. ERS Assemblies. www.ersnet.org/the-society/assemblies

6 European Respiratory Society. Continuing Professional Development. www.ersnet.org/professional-development/cpd 